\title{
The clinical use of somatostatin analogues in the treatment of cancer
}

\author{
STEVEN W. J. LAMBERTS \\ ERICP. KRENNING \\ JAN G. M. KLIJN \\ JEAN-CLAUDE REUBI
}

Growth hormone $(\mathrm{GH})$ release-inhibiting activity was originally detected accidentally during investigations into the distribution of $\mathrm{GH}$ releasing factor in the rat hypothalamus (Krulich et al, 1968). Thereafter it was shown that this $\mathrm{GH}$ release-inhibiting peptide, called somatostatin, is a cyclic peptide consisting of 14 amino acids (Brazeau et al, 1973). The phylogeny, the anatomic distribution, the mechanisms of action, and the functional significance of somatostatin have been reviewed in detail by Reichlin (1983a,b).

The name somatostatin is, in fact, inappropriate because the peptide is distributed widely throughout the body in cells which have nothing to do with the regulation of $\mathrm{GH}$ secretion. In the hypothalamus somatostatin is a neurohormone which reaches the pituitary gland via the portal circulation, where it inhibits the secretion of normal $\mathrm{GH}$ and thyrotrophin (thyroid stimulating hormone, TSH). Somatostatin is also present in high amounts throughout the central and peripheral nervous system, where it influences a variety of functions as a neurotransmitter or neurohormone. The peptide is also found in discrete secretory cells of classical epithelial appearance in all parts of the stomach and the gut where it inhibits, via autocrine and paracrine actions, the secretion of gastrin, pepsin and hydrochloric acid in the stomach, bile secretion, and the release of secretin and vasoactive intestinal polypeptide. The secretion of somatostatin into the lumen of the digestive tract ('lumone'), influences the contractility of the gastro-intestinal tract and the absorption of fluids. Finally, somatostatin inhibits both exocrine and endocrine pancreatic function; apart from an inhibitory effect on pancreatic fluid, bicarbonate and enzyme production, somatostatin (produced in the D-cells of the pancreatic islets) influences carbohydrate metabolism via paracrine inhibitory actions on the release of insulin and glucagon (see Guillemin, 1978; Reichlin, 1983a,b).

Somatostatin, therefore, is present and plays an inhibitory role in the normal regulation of at least three organ systems of humans and other species: (i) the central nervous system, the hypothalamus and the pituitary

Baillière's Clinical Endocrinology and MetabolismVol. 4, No. 1, March 1990 ISBN $0-7020-1467-2$ 
gland; (ii) the gastro-intestinal tract; (iii) the exocrine and endocrine pancreas. It was thus expected to be of therapeutic value in clinical conditions involving hyperfunction of these systems. However, the multiple simultaneous effects of somatostatin in these organ systems, the need for intravenous administration of the peptide, its short duration of action (halflife in the circulation of about $3 \mathrm{~min}$ ), and the post-infusion rebound hypersecretion of hormones greatly diminished the initial enthusiasm for its clinical use (Guillemin, 1978).

Many attempts have been made in recent years to synthesize analogues of somatostatin that do not have the disadvantages of the native peptide. Preliminary clinical and preclinical results with several different analogues have been reported (Vale et al, 1978; Cai et al, 1986; Gottesman et al, 1986). Using step-by-step modification of the conformationally-stabilized, central, essential part of the somatostatin molecule, Bauer et al (1982) succeeded in synthesizing an analogue which did not have most of the disadvantages of the native peptide. In monkeys this analogue, code named SMS 201-995 (Sandostatin, octreotide, see Figure 1) inhibits the secretion of $\mathrm{GH}$, glucagon and insulin 45,11 , and 1.3 times more actively, respectively, than native somatostatin. It is currently unknown why Sandostatin inhibits GH secretion more powerfully than insulin secretion. The analogue is highly resistant to enzymatic degradation which explains its much longer and more powerful inhibitory effect on $\mathrm{GH}$ secretion.

Pharmacokinetic studies showed that a single subcutaneous injection of $50 \mu \mathrm{g}$ of Sandostatin in normal subjects resulted, after $30-60 \mathrm{~min}$, in peak plasma drug concentrations of $1.9-2.7 \mathrm{ng} / \mathrm{ml}$, and that it has an elimination half-life of $113 \mathrm{~min}$ (del Pozo et al, 1986). Although not yet of therapeutic interest, it was shown thereafter that the oral administration of $2 \mathrm{mg}$ of this analogue together with $75 \mathrm{~g}$ of glucose also resulted in 'therapeutic' levels in

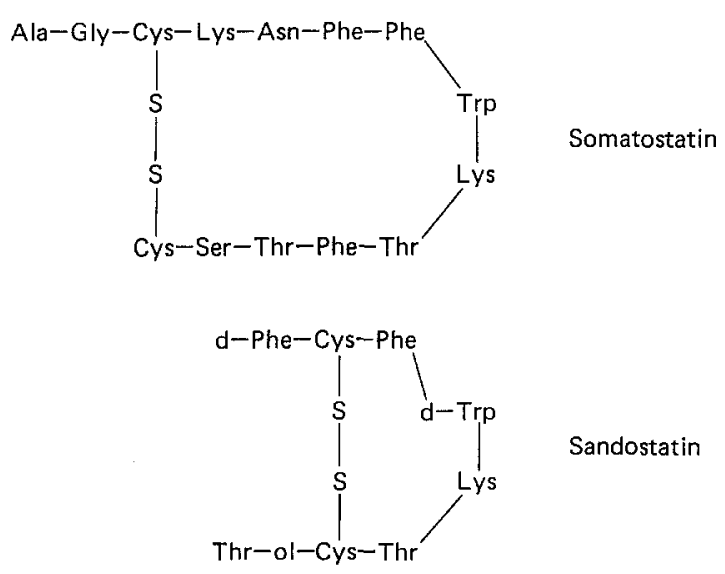

Figure 1. The amino acid sequences of natural somatostatin and the synthesized analogue Sandostatin. 
the circulation (Williams et al, 1986). A rather unexpected observation with regard to the inhibitory effect of Sandostatin on hormone secretion is the absence of rebound hypersecretion (Lamberts et al, 1985a). Figure 2 shows the course of the plasma GH concentrations of one of our acromegalic patients on subsequent days when a placebo or $50 \mu \mathrm{g}$ Sandostatin was administered subcutaneously at $8.15 \mathrm{am}$. The analogue suppressed circulating $\mathrm{GH}$ levels almost completely for $8-10 \mathrm{~h}$, after which they returned slowly to control values.

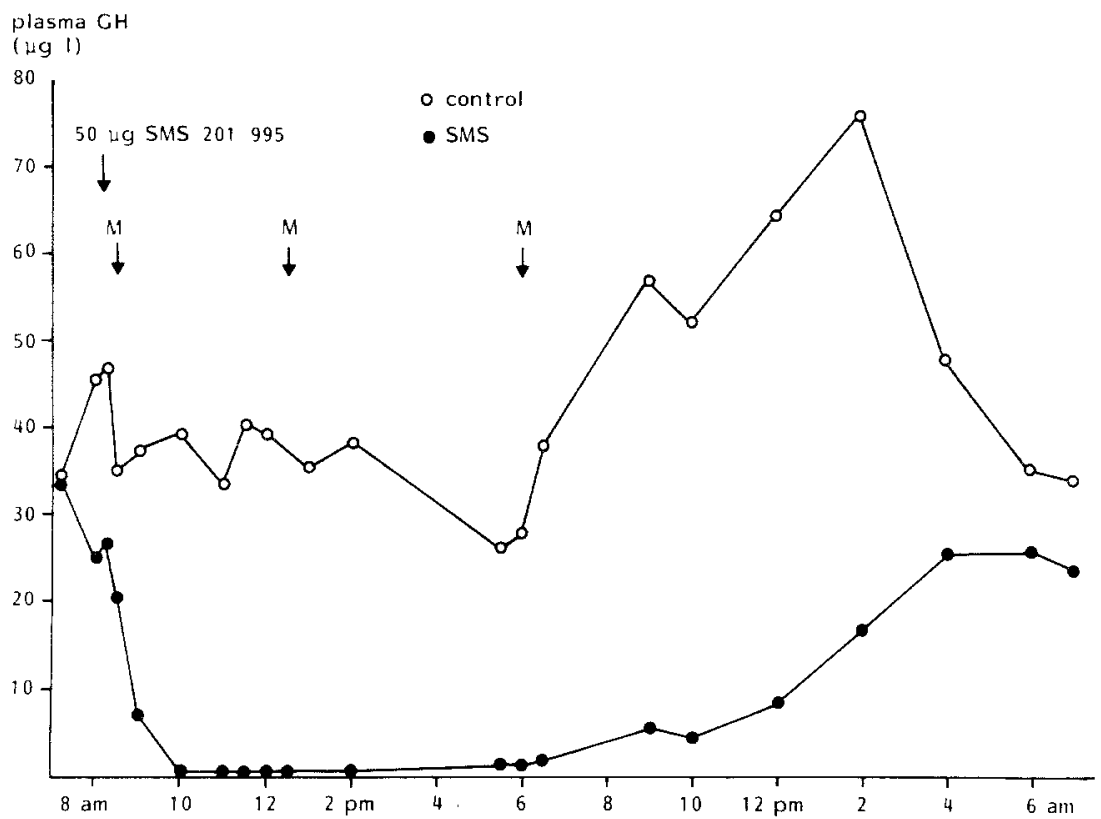

Figure 2. The effect of the subcutaneous administration of $50 \mu \mathrm{g}$ Sandostatin (SMS 201-995) at $8.15 \mathrm{~h}$ on plasma GH levels (--) in an untreated acromegalic patient in comparison with the effect of a placebo at $8.15 \mathrm{~h}$ on another day $\left(\mathrm{O}_{--} \mathrm{O}\right)$.

\section{ACROMEGALY}

The potential use of somatostatin analogues like Sandostatin in the longterm control of tumoral hypersecretion of hormones has been demonstrated most clearly in patients with GH-secreting pituitary tumours. A single subcutaneous injection of $50 \mu \mathrm{g}$ of Sandostatin suppressed mean GH levels after $2-6 \mathrm{~h}$ to less than $5 \mu \mathrm{g} / \mathrm{l}$ in 24 of 41 , and by more than $50 \%$ in 34 of 41 acromegalic patients (Lamberts et al, 1986b). High numbers of high-affinity somatostatin receptors have been detected on most GH-secreting pituitary tumours removed from acromegalic patients (Reubi and Landolt, 1984). Recently Reubi and Landolt (1989) showed that in acromegalics the response of GH to Sandostatin in vivo was closely related to the number of somatostatin receptors which were present on the tumour tissue obtained at subsequent trans-sphenoidal operation. 
Several reports have been published which show that most acromegalic patients respond very well clinically to chronic therapy with Sandostatin (Plewe et al, 1984; Ch'ng et al, 1985; Lamberts et al, 1985b; Oppizzi et al, 1986; Lamberts et al, 1987b). Therapy with 200-300 $\mu \mathrm{g}$ Sandostatin daily in two or three injections caused a marked clinical improvement within days or weeks in virtually all patients, with a diminution or disappearance of complaints like excessive perspiration, headaches, paraesthesias and fatigue. After weeks or months of therapy regression of soft tissue swelling and even of facial coarsening was noted. The mean $24 \mathrm{~h} \mathrm{GH}$ levels decreased during therapy by more than $80 \%$.

The extent of GH suppression during chronic Sandostatin therapy can be predicted from the initial acute response of $\mathrm{GH}$ to a single dose of $50 \mu \mathrm{g}$ of the drug (Lamberts et al, 1988c). During chronic therapy with Sandostatin, a tendency remained for the $\mathrm{GH}$ levels to increase towards the next injection (Lamberts et al, 1985b). However, this tendency diminished over time in most patients (Lamberts et al, 1987b). Of great interest is the observation that the initially raised serum concentrations of somatomedin-C (Sm-C, insulinlike growth factor I, IGF-I) declined during Sandostatin therapy in parallel with the decrease in the mean $24 \mathrm{~h}$ GH levels. In Figure 3 the course of the mean $24 \mathrm{~h} \mathrm{GH}$ and the Sm-C levels of eight acromegalic patients is shown

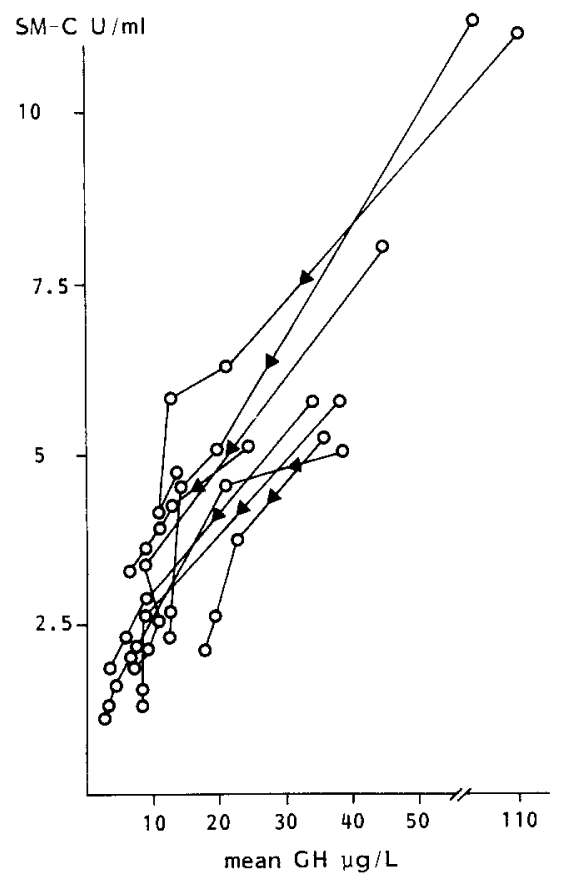

Figure 3. The course of serum Somatomedin-C (Sm-C/IGF-I) and the mean 24-h GH concentrations in eight acromegalic patients during therapy for 2 years with $200-300 \mu g$ Sandostatin daily. (The upper limit of normal of $\mathrm{Sm}-\mathrm{C}=2.2 \mathrm{U} / \mathrm{ml}$.) 
during long-term treatment with Sandostatin ( $300 \mu \mathrm{g}$ daily) for 24 months. A complete normalization of $\mathrm{Sm}-\mathrm{C}$ levels was eventually achieved in more than $50 \%$ of the acromegalic patients. So, it seems possible to manipulate the circulating levels of one of the proven tumour growth factors (IGF-I) by chronic administration of an analogue of an endogenous inhibitory tissue 'growth' factor.

A decrease in pituitary tumour size during Sandostatin treatment was observed on computerized tomography scanning in more than half the acromegalic patients (Lamberts et al, 1985b, 1987b; Barkan et al, 1988). Tumour size reduction, however, was less impressive than that observed during bromocriptine treatment of most prolactin (PRL)-secreting pituitary tumours. Tumour shrinkage has been suggested to occur via a decrease in the size of individual tumour cells caused by their decreased hormonal content, rather than via a cytotoxic effect of Sandostatin (Lamberts et al, $1987 b, 1988 \mathrm{c}$; for review see Lamberts, 1988). The marginal shrinkage of the pituitary tumours during Sandostatin therapy might be partially explained by two recent observations: (i) Reubi et al (1987b) visualized somatostatin receptor sites on a number of $\mathrm{GH}$-secreting tumours and showed that their distribution is often heterogeneous, suggesting that considerable numbers of tumour cells are not sensitive to somatostatin; (ii) Hofland et al (1989) recently showed by studying hormone release of individual human pituitary tumour cells with the reverse haemolytic plaque assay, that in most tumours only a minority of tumour cells release the majority of the total amount of $\mathrm{GH}$ produced. Especially these 'active' tumour cells seem sensitive to Sandostatin, while the majority of the less active tumour cells hardly respond.

Acromegaly often causes distressing disfigurement and a variety of complaints. When treated ineffectively it approximately doubles mortality at all ages as a result of cardiovascular disease associated with hypertension, diabetes mellitus and cancer. Effective and safe long-term medical treatment with Sandostatin is of great benefit in as many as $30-35 \%$ of acromegalics, in whom trans-sphenoidal surgery was unsuccessful or contraindicated, or in those patients in whom the effects of radiotherapy have to be awaited (for review see Lamberts, 1988). There seems little doubt that Sandostatin is in general superior to dopamine agonist therapy with bromocriptine (Lamberts et al, 1986c), but the side-effects of long-term Sandostatin treatment will need evaluation (see below).

\section{OTHER PITUITARY TUMOURS}

Somatostatin is, under normal conditions, a physiological inhibitory regulator of GH secretion. However, somatostatin also reaches the other anterior pituitary cells. An inhibitory response to somatostatin of hormone secretion by normal corticotrophs, lactotrophs and thyrotrophs, however, depends mainly on the microenvironment of these cells, especially with regard to their own feedback hormones. In the absence of glucocorticoids the corticotrophs are sensitive to the inhibitory effect of somatostatin 
(Lamberts et al, 1989b); in the presence of increasing oestradiol concentrations, dopamine sensitivity of the lactotroph decreases while the sensitivity to somatostatin increases to the same extent, and in the absence of thyroid hormone the thyrotroph is more sensitive to somatostatin (Lamberts et al, $1989 \mathrm{~b}$ ). These changes are probably not mediated via postreceptor effects but seem to be regulated via a change in the number and/or affinity of somatostatin receptors on these respective cells (Viguerie et al, 1987). Interestingly somatostatin receptors remain present on many human pituitary tumours which originate from adrenocorticotrophic hormone (ACTH), TSH and PRL cells, but also on part of non-functioning pituitary tumours (Reubi et al, 1987b). This makes these patients good candidates for treatment with long-acting somatostatin analogues. Indeed inhibition of hormone release and tumour shrinkage have been reported during therapy with Sandostatin in patients with TSH- and infiltrating ACTH (Nelson's Syndrome) secreting pituitary tumours (Comi et al, 1986; Guillausseau et al, 1987; Lamberts et al, 1989a).

\section{SIDE-EFFECTS OF SANDOSTATIN THERAPY}

Sandostatin was reported to be well tolerated in most patients (Lamberts et al, 1985b, 1987b; Kvols et al, 1986, 1987). Gastro-intestinal reactions are common during the first days of therapy; these consist of crampy abdominal pains, flatulence, loose stools, diarrhoea and steatorrhoea. The increase in the fat content of the faeces during Sandostatin therapy is only minimal in most patients and normalizes spontaneously after a few weeks. No nutritional deficiencies related to malabsorption have been reported. In a few patients gallstone formation was observed, which might be a side-effect of long-term treatment with Sandostatin.

Because of its inhibitory action on insulin release Sandostatin may impair postprandial glucose tolerance. However, during chronic therapy with Sandostatin in doses as high as $450 \mu \mathrm{g} / \mathrm{day}$, no clinically significant deterioration of glucose tolerance was observed in 50 patients with acromegaly, endocrine pancreatic tumours and carcinoids (Lamberts et al, 1985b, 1987b; Kvols et al, 1986, 1987). It is not yet known whether the induction of a mild diabetic state during Sandostatin treatment, will give rise to the development of secondary complications as seen in diabetic patients. Interestingly, no desensitization, tachyphylaxis, or down-regulation of the effect of Sandostatin on 'normal' insulin secretion was noted in acromegalic patients treated for up to 2 years (Lamberts et al, 1987b).

\section{ENDOCRINE PANCREATIC TUMOURS}

Functional endocrine tumours originating from the neuroendocrine peptidesecreting cells of the endocrine pancreas and of the gastro-intestinal tract are relatively rare. The majority of these tumours originate from the pancreas but they may also occur in the stomach, the duodenum or intestines (Bloom and 
Polak, 1980). These tumours secrete polypeptide hormones and traditionally their name is derived from the specific clinical syndromes caused by the hypersecretion of the hormones (e.g. gastrinomas, glucagonomas, vipomas, insulinomas). Often these tumours start to secrete other hormones during the follow-up, which then leads to the appearance of new clinical syndromes (Wynick et al, 1988).

With the exception of insulinomas most tumours are malignant and in many patients metastases are present at the time of initial clinical presentation (Stefanini et al, 1974). The optimal treatment of malignant endocrine pancreatic tumours has not yet been established. Surgery is the primary treatment, but debulking of the tumour is often the only option when metastases in lymph nodes and especially in the liver are present at operation. Palliative treatment with cytostatic drugs (Moertel et al, 1980) has been shown to result in transient improvement in about $35 \%$ of patients. However, none of these treatments cures the disease and the often distressing clinical symptomatology of most patients is especially difficult to control. However in some instances symptomatic treatment can be achieved. For example non-competitive $\mathrm{H}_{2}$-blocking drugs successfully block the hypersecretion of gastric acid in most gastrinoma patients (Lamers et al, 1984).

Sandostatin has been shown to be especially beneficial in the treatment of the clinical syndromes caused by hypersecretion of hormones: severe diarrhoea, dehydration and hypokalaemia, peptic ulceration, life-threatening attacks of hypoglycaemia and necrolytic skin lesions can be well controlled during chronic therapy with $100-450 \mu \mathrm{g}$ Sandostatin daily in most patients with pancreatic tumours secreting VIP, gastrin, insulin and glucagon (Bonfils, 1985; Maton et al, 1985; Wood et al, 1985; Anderson and Bloom, 1986; O'Dorisio, 1986; Vinik et al, 1986; Kvols et al, 1987; Eriksson et al, 1988; Woltering et al, 1988). Even the often very aggressive form of Cushing's syndrome caused by ectopic secretion of ACTH from a metastatic gastrinoma was well controlled in several patients during Sandostatin treatment (Lamberts et al, 1988b; Ruszniewski et al, 1988).

Summarizing the experience of Sandostatin therapy in patients with metastatic endocrine pancreatic tumours several conclusions can be drawn:

1. The initial clinical response to Sandostatin therapy seems mainly dependent on the presence of somatostatin analogue receptors on these tumours. Analysing a group of 18 metastatic endocrine pancreatic tumours we found high affinity binding sites for the tyr ${ }^{3}$-derivative of Sandostatin on 14 of them (see Table 1 and Reubi et al, 1987a).

Table 1. The presence of somatostatin receptors on endocrine pancreatic tumours of 18 patients.

\begin{tabular}{lcc}
\hline & \multicolumn{2}{c}{ Somatostatin analogue (204-090) receptors } \\
\cline { 2 - 3 } Type of tumour & Positive & Negative \\
\hline Gastrinoma & 6 & 0 \\
Insulinoma & 4 & 3 \\
Vipoma & 4 & 1 \\
& 14 & 4 \\
\hline
\end{tabular}


Interestingly in insulinomas little or no binding with Sandostatin was observed in several cases, while simultaneously binding studies with somatostatin- 28 showed high numbers of receptors for this endogenous peptide (Reubi et al, 1987a). In one of these insulinoma patients the acute administration of $50 \mu \mathrm{g}$ Sandostatin resulted in an acute hypoglycaemic attack: tumorous hypersecretion of insulin was not affected, but the release of the counter-regulatory hormones glucagon and GH, was suppressed by Sandostatin, and probably associated with delay in time of transit through the gut and of glucose absorption. Therefore it seems advisable to select insulinoma patients for Sandostatin therapy only after a well-controlled trial in which the first dose of the drug is administered in hospital where glucose can be administered intravenously if necessary. In this regard it is interesting to note that neonatal hypoglycaemia in newborns with nesidioblastosis can be controlled with Sandostatin (Bruining et al, 1986).

2. The duration of the beneficial effects of Sandostatin on clinical symptomatology of patients with metastatic endocrine pancreatic tumours is highly variable. Mild worsening of symptoms and increasing tumourrelated hormone concentrations were observed during long-term therapy with Sandostatin, but increasing the dose of the analogue initially reversed these problems in most patients (Anderson and Bloom, 1986; Williams et al, 1987). Some beneficial effects of Sandostatin in this type of patient, like a decrease in contractility of the gastro-intestinal tract, may be direct and not mediated via the inhibition of tumoral hormone secretion. Often these beneficial effects will remain even if the sensitivity of the tumours to Sandostatin declines. Eventually tumour cells without somatostatin receptors will develop, and the therapeutic effect of Sandostatin decreases in parallel with signs and symptoms of tumour progression. Unfortunately, however, in exceptional cases a sudden escape from Sandostatin can also occur early after the initiation of therapy. This resistance to Sandostatin might well be caused by down-regulation of the somatostatin receptors on these tumours. Indeed somatostatin receptor down-regulation is demonstrable under certain experimental conditions, although it is not yet proven to occur in resistant tumours (Viguerie et al, 1987). The sudden occurrence of insensitivity to Sandostatin is clinically of potential danger especially in vipoma and insulinoma patients where hypokalaemic acidosis, dehydration and hypoglycaemic attacks can suddenly reappear (Koelz et al, 1987; Lamberts et al, 1988a).

3. There is very little evidence so far that Sandostatin controls tumour growth in this type of patient. Most patients treated chronically with Sandostatin had metastatic disease initially, especially affecting the liver. Gorden (1989) summarized the literature and reported that out of a total of 46 patients (five insulinoma, 16 gastrinoma, ten vipoma, eight glucagonoma and seven other islet cell tumours), who were treated chronically with Sandostatin in a dose varying between 200 and $1500 \mathrm{~g} /$ day, tumour size increased in 20 , remained unchanged in 18 and actually decreased in eight patients. 
4. The place of Sandostatin in the treatment of patients with metastatic endocrine pancreatic tumours reflects its high efficacy in controlling the clinical signs and symptoms caused by hypersecretion of hormones. A high success rate with regard to a decrease in stool volume, improvement of systemic electrolyte and fluid imbalance, healing of skin lesions and peptic ulceration and a decrease in the number of attacks of hypoglycaemia can be expected. In this respect Sandostatin is able to improve the quality of life in most of these patients, while also the duration of the stay in hospital and the number and the severity of the life-threatening complications related to hormonal hypersecretion diminish. However, Sandostatin is a palliative therapy and it will hardly affect or change the classic therapeutic approach in this type of patient, which consists of surgery (debulking) and selective arterial embolization of the tumour and its metastases. In our opinion Sandostatin therapy can be tried, however, as a second line of therapy, while cytotoxic therapy with drugs like streptozotocin must be considered thereafter when the sensitivity of the tumour to Sandostatin declines.

\section{CARCINOIDS}

Carcinoids are often malignant tumours which originate from enterochromaffin cells throughout the body, but especially from the gastrointestinal tract and the lung (Pearse et al, 1974). Patients with the metastatic carcinoid syndrome experience attacks of flushing, diarrhoea and sometimes wheezing and right heart failure because of tricuspid valve insufficiency. The symptoms are related to hypersecretion of serotonin and tachykinins by carcinoids. However, especially in carcinoids derived from the foregut and midgut, clinical symptomatology occurs when metastases have developed which secrete their products directly in the systemic circulation (e.g. liver metastases). Because most carcinoids are relatively slowgrowing tumours, the symptoms caused by the biochemical products secreted by the tumour dominate the clinical picture. These patients frequently become invalided by the severe diarrhoea, flushing attacks and congestive heart failure. Many carcinoid patients die from the complications of long-standing hormonal hypersecretion, rather than from tumour progression (Kvols et al, 1986; Hodgson and Maton, 1987).

Kvols et al (1986) carried out careful studies on the effects of Sandostatin treatment of patients with the malignant carcinoid syndrome. Chronic therapy with $450 \mu \mathrm{g}$ Sandostatin daily caused an impressive symptomatic and biochemical response in virtually all 25 patients studied. Flushing and diarrhoea associated with the syndrome were promptly relieved in 22 patients. Eighteen of the 25 patients had a decrease of $50 \%$ or more in their urinary 5-hydroxyindolacetic acid excretion, as compared with the pretreatment values. The median duration of this biochemical response was more than 12 months. Thirteen of these patients had tumours that could be assessed objectively by linear or bidimensional measurements. In eight of these patients, the tumour remained unchanged, whereas (incomplete) 
tumour regression was observed in the other five patients during Sandostatin therapy. A recent study of 35 carcinoids showed that $80 \%$ of the tumours contained a high density of somatostatin receptors (Reubi et al, unpublished data).

The current optimal therapy of malignant carcinoid disease seems comparable to that advocated for metastatic endocrine pancreatic tumours (see above). Surgical debulking only alleviates symptomatology, but many patients are in a bad clinical condition. Sandostatin has been shown to control effectively acute hypertension in carcinoid crises, as they can occur during anaesthesia (Kvols, 1986). Arterial embolization of the tumour and its metastases has been shown to be temporarily effective in some patients (Maton et al, 1983). Chemotherapy with combinations of agents, often including streptozotocin, is in most patients disappointing (Kvols, 1986). In a recent review Hodgson (1988) concluded that symptomatic control of hormonal hypersecretion with simple blocking agents like serotonin-blockers (ketanserin) and, if this is not effective, Sandostatin is the primary treatment of the metastatic carcinoid syndrome. The quality of life improves dramatically during Sandostatin therapy while the occurrence of secondary complications like cachexia, dehydration, tachyarrhythmias, congestive heart failure and bronchoconstriction are delayed. We suspect that these beneficial effects of Sandostatin will be shown to contribute significantly to longer survival of these patients. Whether or not the drug also controls tumour growth remains unanswered at present. Eventually, when the tumour becomes insensitive to Sandostatin, embolization, surgical debulking and chemotherapy should be considered.

\section{EFFECTS IN EXPERIMENTAL TUMOURS}

Somatostatin analogues have been shown to inhibit the growth of a variety of transplantable tumours in different animals (see Lamberts et al, 1987a; Schally, 1988). The subcutaneous administration of natural somatostatin and three different analogues in doses of $30 \mu \mathrm{g}$, once or twice daily for 14-30 days to rats bearing the Swarm chondrosarcoma reduced tumour volume and/or weight significantly (Redding and Schally, 1983). Chronic administration of Sandostatin $(1.25 \mathrm{mg} / \mathrm{kg} / \mathrm{day}, 5$ days per week for 5 weeks) inhibited tumour volume of these chondrosarcomas by $48 \%$ (Reubi, 1985). Somatostatin analogues inhibit tumour growth and prolong the survival of mice bearing the Dunn osteosarcoma (Cai et al, 1986), and inhibited the growth of acinar pancreatic carcinomas in rats (Redding and Schally, 1984; Klijn et al, 1988), a ductal pancreatic adenocarcinoma growing in hamsters (Cai et al, 1986), the transplantable prolactin-secreting rat pituitary carcinoma 7315a (de Quijada et al, 1983; Lamberts et al, 1986a), transplantable insulinomas in hamsters (Reubi, 1985), the MT/W9A mammary adenocarcinoma in the rat (Cai et al, 1986) and the Dunning $\mathrm{R} 3327 \mathrm{H}$ prostate carcinoma in the rat (Cai et al, 1986; Siegel et al, 1988). In addition somatostatin analogue administration has been shown to inhibit effectively the growth of transplanted human adenocarcinomas of the pancreas (Upp et 
al, 1988) and the colon (Palmer Smith and Solomon, 1988) and human small cell lung cancers (Taylor et al, 1988a) which were transplanted in nude mice.

Somatostatin analogues seem to exert their inhibitory action on tumour growth in the experimental tumours mentioned above via one or more of the following mechanisms (Table 2; Reubi, 1985; Lamberts et al, 1986a):

1. Inhibition of the secretion of hormones which are involved in the regulation of tumour growth, like $\mathrm{GH}$, insulin and/or other hormones of the gastro-intestinal tract;

2. Direct or indirect (via $\mathrm{GH}$ ) inhibition of the formation of IGF-I and/or other growth factors which exert a stimulatory effect on the growth of tumours;

3. Inhibition of angiogenesis. O'Dorisio (1986) showed in several in vitro models that Sandostatin exerts a powerful inhibitory effect on angiogenesis especially if this is evoked (Fassler et al, 1988);

4. A direct inhibitory effect on the tumour.

Table 2. Mechanism of action of the tumour growth inhibitory effects of somatostatin analogues.

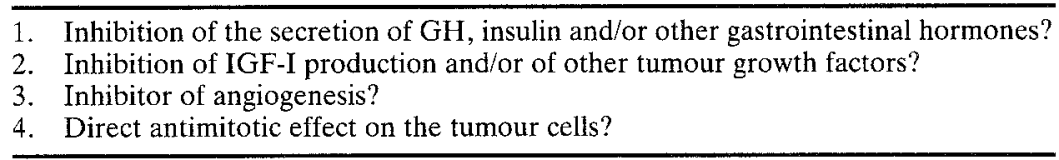

Actions 1 and 4 may be receptor-mediated.

Mechanisms 1 and 4 may be mediated via specific somatostatin receptors.

This last mechanism of action of a direct antiproliferative effect of somatostatin (analogues) seems to be of considerable importance. Somatostatin inhibits DNA synthesis and cell replication induced by epidermal growth factor (EGF) both in gerbil fibroma and Hela cells (Mascardo and Sherline, 1982). Both native somatostatin and two of its analogues directly inhibit the proliferation of the human breast cancer cell line MCF-7 (Setyono-Han et al, 1987), while direct antiproliferative effects of Sandostatin on primary breast cancer cell lines were also reported (Scambia et al, 1988). In a human pancreatic cancer cell line (MIA PaCa-2) somatostatin was shown to reverse EGF-stimulated cell growth (Liebow et al, 1986), while somatostatin also selectively suppressed insulin-induced proliferation of cultured human hepatoma cells (Chou et al, 1987). In Figure 4 Sandostatin is shown to reverse both basal and the IGF-I (somatomedin-C)induced stimulation of PRL release and thymidine incorporation in the cultured tumour cells prepared from a transplantable pituitary carcinoma (Lamberts et al, 1986a). In several of these models, the tumours were shown to contain somatostatin receptors. These data and those presented at the beginning of the chapter suggest that somatostatin may be one of a class of hormones that act as endogenous tumour growth inhibitors or as modulators of growth stimulatory peptides.

Several observations from studies with transplantable tumours have shown that the dose and schedule of administration of somatostatin 


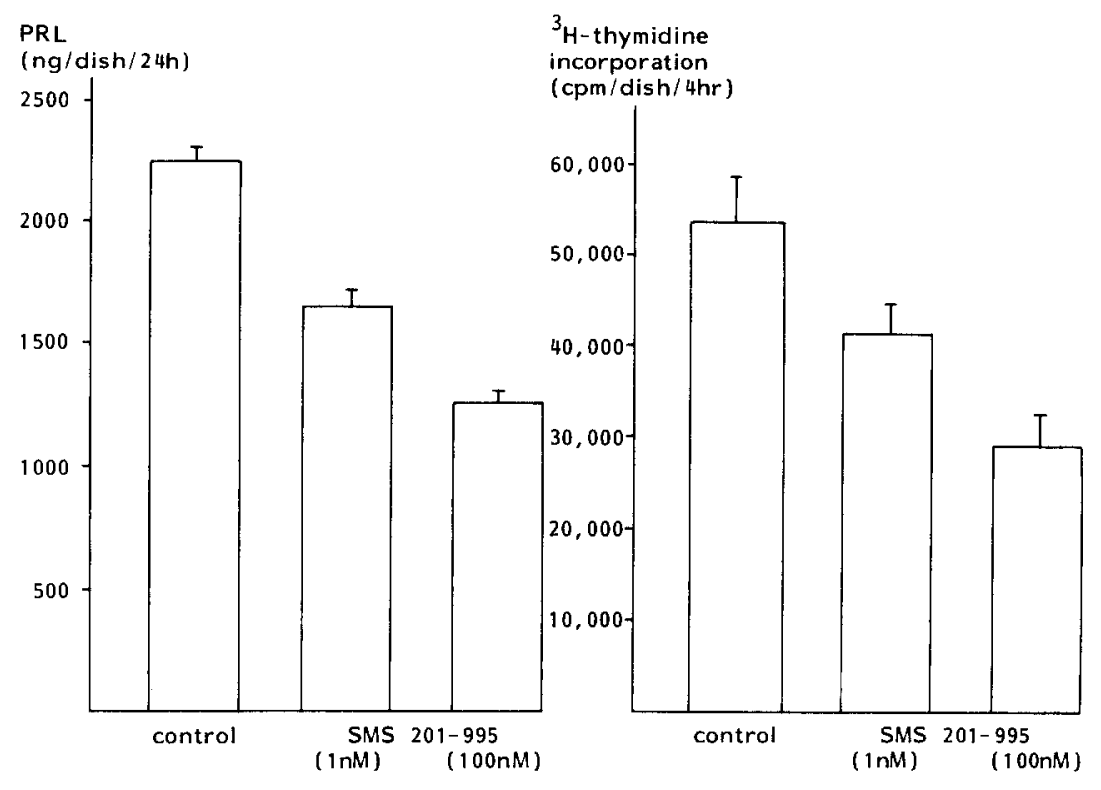

Figure 4. The effect of Sandostatin (SMS 201-995) on PRL release and ${ }^{3} \mathrm{H}$-thymidine incorporation by cultured cells prepared from the transplantable PRL-secreting rat pituitary tumour 7315 b (mean \pm SEM; 4 dishes per group).

analogues may be important factors in the development of desensitization or tachyphylaxis of their inhibitory effects on plasma GH, insulin and/or IGF-I concentrations. This is especially important in the rat (Lamberts et al, $1987 \mathrm{c}$ ), but might also pertain to studies in man (Klijn et al, unpublished data). In addition, the occurrence of 'down-regulation' of somatostatin receptors on tumours during chronic therapy with somatostatin analogues might also play an important role in determining the ultimate effect of therapy with these analogues on tumour growth (Koper et al, 1989).

\section{SOMATOSTATIN RECEPTORS ON HUMAN TUMOURS}

We have tested a wide variety of human tumours originating from different organs for the presence of specific somatostatin receptors. The techniques used included somatostatin receptor autoradiography and biochemical characterization of receptor-positive tumours with an in vitro binding assay showing saturable and high affinity receptors with pharmacological specificity for somatostatin (Reubi and Maurer, 1985; Reubi et al, 1986a).

As mentioned above, somatostatin receptors were observed on most GH-producing pituitary adenomas (Reubi and Landolt, 1984) and most endocrine pancreatic tumours and carcinoids (Reubi et al, 1987a,d). An example of somatostatin receptor autoradiography is shown in Figure 5.

In addition, all 27 human meningiomas contained considerable numbers 


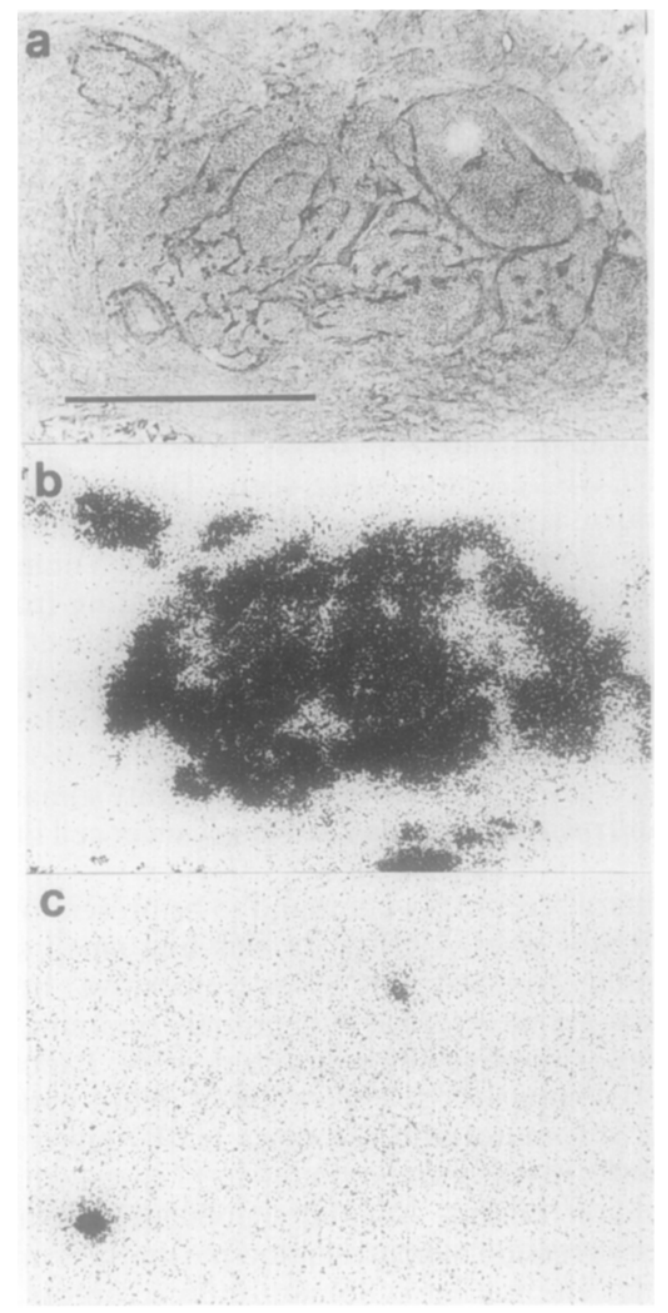

Figure 5. Somatostatin receptors in a case of a human vipoma. (a) Haematoxylin-eosin stained section. (b) Autoradiogram showing total bindings of ${ }^{125} \mathrm{I}-204-090$. (c) Audoradiogram showing non-specific binding (in presence of $10^{-6} \mathrm{M} 204-090$ ). Bar $=1 \mathrm{~mm}$.

of somatostatin receptors (Reubi et al, 1986b, 1989). Receptor density varied among tumours from low levels to more than $400 \mathrm{fmol}$ per $\mathrm{mg}$ protein. The tumours had saturable and high affinity receptors with pharmacological specificity for somatostatin. Interestingly the normal human leptomeninx also contains somatostatin binding sites (Reubi et al, 1986c). Somatostatin receptors were found on all 27 meningiomas studied and EGF receptors were found on 23 of them (Reubi et al, 1989). In some cases the coincidental presence of both receptors on the same tumour cells could be excluded: the EGF receptors were found especially at the more 
'active' necrotic part of the tumour, while somatostatin receptors were mainly found on the surrounding tumour tissue. No effect of Sandostatin was observed on basal or EGF-stimulated growth of meningiomas in culture.

In glia-derived tumours, there was an inverse relationship between the incidence of somatostatin receptors and EGF receptors in individual tumours (Reubi et al, 1987c, 1989b): in a majority (five of eight) welldifferentiated astrocytomas (grade I-II), somatostatin receptors were present, but in none (zero of eight) were EGF receptors detected. In undifferentiated glioblastomas, the reverse situation was observed: no somatostatin receptors were found ( 0 of 14), but EGF receptors were present in the majority of tumours ( 8 of 14). In grade III astrocytomas both somatostatin and EGF receptors were seen. These data suggest that in glia-derived tumours, somatostatin receptors are markers for the welldifferentiated cases as opposed to EGF receptors. High numbers of somatostatin receptors were found in two tumours originating from neuroblasts, i.e. ganglioneuroblastoma and medulloblastoma (Reubi et al, 1987c,d).

No somatostatin receptors were found on prostatic, ovarian, endometrial and primary liver cell carcinomas (Reubi et al, 1987d). In addition no somatostatin receptors could be detected on any of 12 exocrine pancreatic carcinomas (Reubi et al, 1988). However, high affinity somatostatin binding sites were also found on a human small cell lung cancer cell line (Taylor et al, 1988b).

Finally somatostatin receptors were found to be present on human breast cancer samples (Reubi et al, 1987d). In this first small series including primary and secondary tumours only $8 \%$ were positive. In the two subsequent, larger studies, which included only primary tumours, $15 \%$ of the 210 samples were receptor-positive (Foekens et al, 1989; Papotti et al, 1989). Papotti et al (1989) compared the expression of neuro-endocrine markers with the presence of somatostatin receptors in 100 human breast cancer samples. Somatostatin receptors were found in 17 cases, while nine showed neuro-endocrine characteristics. A highly significant correlation was established between the expression of neuro-endocrine markers and somatostatin receptor density on these tumours. Somatostatin receptors were found on $15 \%$ of 110 human breast cancer samples (Foekens et al, 1989). The relapsefree survival for patients with tumours containing somatostatin receptors was significantly longer than for patients with somatostatin receptornegative tumours ( $82 \%$ versus $46 \%$ disease-free after 6 years).

\section{SOMATOSTATIN RECEPTOR IMAGING IN VIVO}

High numbers of specific binding sites with a high affinity for somatostatin have been found on a variety of human tumours. In autoradiographic studies a sharp difference was observed between the presence of receptors on the tumour tissue, and low numbers of receptors in the surrounding normal tissue. In addition a much longer inhibitory effect of Sandostatin on tumorous hormone secretion, e.g. GH-secreting pituitary tumours compared with 
normal GH release in man, also points to a selective powerful binding and effect of the analogue at the site of the tumour which is probably caused by the higher number and/or higher affinity of the somatostatin receptors on these tumours. These observations led us to explore, whether it might be possible to detect somatostatin receptor-positive tumours in vivo by administration of an analogue labelled with radioactive iodine (Krenning et al, 1989). 204-090 is a somatostatin analogue with tyrosine in position 3 , rather than phenylalanine which is present at that place in Sandostatin. The biological activities of Sandostatin and 204-090 are similar. ${ }^{123}$ I-bound 204-090 (37-555 MBQ) was injected intravenously in patients suspected to have somatostatin receptorpositive tumours and planar or ECT images were made with a gamma camera. After the bolus injection of radio-iodinated 204-090 rapid accumulation of radioactivity was seen in the liver. About $50 \%$ of the activity was cleared from the blood-pool within $2 \mathrm{~min}$ of intravenous injection. Localization of the primary tumours and their (previously often unknown) metastases with radio-iodinated 204-090 was possible in five of six endocrine pancreatic tumours (the sixth patient had a 204-090 receptor-negative insulinoma) and in all 12 patients with metastatic carcinoid disease. The detection of metastases in lymph nodes, bone and liver points towards the powerful discrimination of this technique. It also confirms previous in vitro observations which showed that metastases of somatostatin receptor-positive tumours remain receptor positive (Reubi et al, 1987a,d). The observed accumulation of radionuclide at the site of the tumour after intravenous injection appears to be instantaneous and prolonged in contrast to the blood-pool activity, which rapidly decreases. An example of a patient with a carcinoid tumour which metastasized into the liver and to a lymph node in the left side of the neck is shown in Figures $6 \mathrm{a}$ and $b$. The in vivo somatostatin receptor-positive imaging technique also revealed that 24 and $48 \mathrm{~h}$ scans in most patients still showed considerable
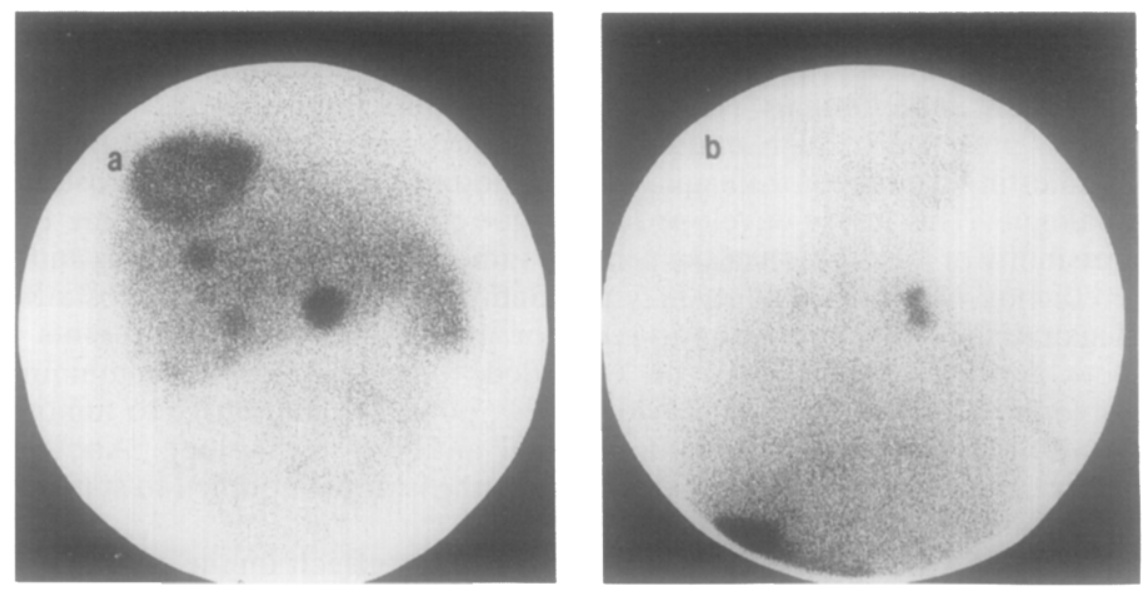

Figure 6. Gamma-camera pictures 30 minutes after the intravenous administration of ${ }^{123}$ I-bound 204-090 in a patient with metastatic carcinoid disease. (a) Liver containing several hot spots representing somatostatin receptor-positive metastases. (b) A lymph node in the left side of the neck which also contains a metastasis from the carcinoid tumour. 
accumulation of radioactivity at the tumour site. This suggests that radiotherapy for this type of carcinoma with $\beta$-emitting radionuclides labelled to somatostatin analogue might be feasible.

This easy, harmless technique was also used in the investigation of other patients with known or unknown somatostatin receptor-positive tumours. Positive scans were obtained in patients with pituitary tumours, neuroblastomas, meningiomas, low-grade astrocytomas and neuro-endocrine tumours like paragangliomas and small cell lung cancers.

\section{SUMMARY AND CONCLUSIONS}

Somatostatin is a regulatory hormone or tissue factor which plays an inhibitory role in the normal regulation of several organ systems, including the central nervous system, hypothalamus and pituitary gland, the gastrointestinal tract and the exocrine and endocrine pancreas. Sandostatin is an analogue of somatostatin which has characteristics which makes it a better compound for clinical use than native somatostatin: it inhibits $\mathrm{GH}$ preferentially over insulin. It has a long half-life in the circulation, causing a prolonged inhibitory effect in somatostatin-responsive target organs. It is active after subcutaneous administration and rebound hypersecretion does not occur. Sandostatin is very well tolerated by most patients.

Somatostatin receptors remain present on a variety of tumours which arise in tissues that contain these receptors normally. High numbers of somatostatin receptors have been found on $\mathrm{GH}$-secreting pituitary tumours and on most metastatic endocrine pancreatic tumours and carcinoids. Sandostatin treatment ameliorates clinical symptoms in most acromegalic patients while GH hypersecretion and elevated concentrations of circulating IGF-I are well controlled. In most patients hormonal hypersecretion from endocrine pancreatic tumours and carcinoids is also suppressed during Sandostatin therapy. This results in an instant improvement in the quality of life. There is preliminary evidence of control of tumour growth.

The presence of high numbers of somatostatin receptors on tumours enables in vivo receptor-imaging, with ${ }^{123}$ iodine coupled to a somatostatin analogue. This newly developed technique provides for the first time the possibility of localization of the primary tumours and their metastases and a prediction of which patients may respond to treatment with Sandostatin. Theoretically this somatostatin-receptor imaging technique represents a new approach which may be extended to other receptor-containing tumours. Therefore it may provide a new, powerful alternative to tumour localization performed with monoclonal antibody technology. Another potential development is the use of $\beta$-emitting isotopes coupled to somatostatin analogues for therapeutic irradiation.

Somatostatin analogues exert potent inhibitory effects on the growth of a variety of experimental tumour models in animals. Several mechanisms of action have been proposed including the direct antiproliferative effects of somatostatin and its analogues in a variety of tumour cell cultures.

Most well-differentiated human brain tumours like meningiomas and 
low-grade astrocytomas contain somatostatin receptors, while undifferentiated brain tumours mainly contain EGF receptors. Fifteen percent of human breast carcinomas contain somatostatin receptors; those which do have a better prognosis.

It can be concluded that somatostatin is an endogenous, naturally occurring inhibitory growth factor. Therapeutic application of its analogue, Sandostatin, is easy and harmless and despite no data being available yet on its potential use in the treatment of cancer, preliminary laboratory results seem promising.

\section{REFERENCES}

Anderson JV \& Bloom SR (1986) Neuroendocrine tumours of the gut: long-term therapy with the somatostatin analogue SMS 201-995. Scandinavian Journal of Gastroenterology 21: $115-128$.

Barkan AL, Lloyd RV, Chandler WF et al (1988) Preoperative treatment of acromegaly with long-acting somatostatin analog SMS 201-995: shrinkage of invasive pituitary macroadenomas and improved surgical remission rate. The Journal of Clinical Endocrinology and Metabolism 67: 1040-1048.

Bauer W, Briner U, Doepfner W et al (1982) SMS 201-995: a very potent and selective octapeptide analogue of somatostatin with prolonged action. Life Science 31: 1133-1141.

Bloom SR \& Polak JM (1980) Glucagonomas, VIPomas and somatostatinomas. Clinical Endocrinology and Metabolism 9: 285-297.

Bonfils S (1985) New somatostatin molecule for management of endocrine tumours. Gut 26: 433-437.

Brazeau P, Vale W, Burgus R et al (1973) Hypothalamic polypeptide that inhibits the secretion of immunoreactive pituitary growth hormone. Science 179: 77-79.

Bruining GJ, Bosschaart AN, Aarssen RSR et al (1986) Normalization of glucose homeostasis by a long-acting somatostatin analog SMS 201-995 in a newborn with nesidioblastosis. Acta Endocrinologica 279(supplement): 334-340.

Cai RZ, Szoke B, Lu R et al (1986) Synthesis and biological activity of highly potent octapeptide analogs of somatostatin. Proceedings of the National Academy of Sciences USA 83: $1896-1900$.

Ch'ng LJC, Sandler IM, Kraenzlin ME et al (1985) Long-term treatment of acromegaly with a long-acting analogue of somatostatin. British Medical Journal 290: 284-285.

Chou C-K, Ho L-T, Ting L-P et al (1987) Selective suppression of insulin-induced proliferation of cultured human hepatoma cells by somatostatin. The Journal of Clinical Investigation 79: $175-178$.

Comi RJ, Gesundheit N, Murray L, Gorden P \& Weintraub BD (1986) Response of thyrotropin-secreting pituitary adenomas to a long-acting somatostatin analogue. New England Journal of Medicine 317: 12-17.

Erikssen B, Oberg K, Andersson T et al (1988) Treatment of malignant endocrine pancreatic tumors with a new long-acting somatostatin analogue, SMS 201-995. Scandinavian Journal of Gastroenterology 23: 508-512.

Fassler JE, Hughes JH, Cataland S \& O'Dorisio TM (1988) Somatostatin analog: an inhibitor of angiogenesis: Seventh International Symposium on Gastrointestinal Hormones, Shizuoka, Japan, abstract no. 2.

Foekens JA, Portengen H, van Putten WLJ et al (1989) Assessment of the prognostic value of receptors for insulin-like growth factor-1, somatostatin, and epidermal growth factor in human breast cancer. Cancer Research (in press).

Gorden P (1989) Somatostatin and somatostatin analogue (SMS 201-995) in treatment of hormone-secreting tumors of the pituitary and gastrointestinal tract and non-neoplastic diseases of the gut. Annals of Internal Medicine 110: 35-50.

Gottesman I, Tobert J, Vandlen R \& Gerich J (1986) Efficacy, pharmacokinetics and 
tolerability of a somatostatin analogue $(\mathrm{L}-363,586)$ in insulin-dependent diabetes mellitus. Life Science 38: 2211-2219.

Guillausseau PJ, Chanson P, Timsit J et al (1987) Visual improvement with SMS 201-995 in a patient with a thyrotropin-secreting pituitary adenoma. New England Journal of Medicine 317: $53-54$.

Guillemin R (1978) Peptides in the brain: the new endocrinology of the neurons. Science 202: 390-402.

Hodgson HJF (1988) Controlling the carcinoid syndrome. British Medical Journal 297: 12131214.

Hodgson HJF \& Maton PN (1987) Carcinoid and neuroendocrine tumours. Baillière's Clinical Gastroenterology 1: 36-61.

Hofland LJ, van Koetsveld PM, van Vroonhoven CCJ, Stefanko SZ \& Lamberts SWJ (1989) Heterogeneity of growth hormone $(\mathrm{GH})$ release by individual pituitary adenoma cells from acromegalic patients, as determined by the reverse hemolytic plaque assay: effects of SMS 201-995, GH-releasing hormone and thyrotropin-releasing hormone. The Journal of Clinical Endocrinology and Metabolism 68: 613-620.

Klijn JGM, Setyono-Han B, Bakker GH, Portengen H \& Foekens JA (1988) Prophylactic neuropeptide-analog treatment of a transplantable pancreatic tumor in rats. In Bresciani F, King RJB, Lippman ME \& Raynaud JP (eds) Hormones and Cancer 3: Progress in Cancer Research and Therapy, vol 35, pp 550-554. New York: Raven Press.

Koeltz A, Kraenzlin M, Gyr K et al (1987) Escape of the response to a long-acting somatostatin analogue (SMS 201-995) in patients with VIPoma. Gastroenterology 92: 527-531.

Koper JW, van Koetsveld P, Hofland LJ \& Lamberts SWJ (1989) Direct growth inhibitory action of sandostatin on rat pituitary $7315 \mathrm{~b}$ tumor cells in vitro. Neuroendocrine Perspectives, in press.

Krenning EP, Breeman WAP, Kooij PPM et al (1989) Localisation of endocrine-related tumours with radioiodinated analogue of somatostatin. Lancet i: 242-244.

Krulich L, Dhariwal APS \& McCann SM (1968) Stimulatory and inhibitory effects of purified hypothalamic extracts on growth hormone release from rat pituitary in vitro. Endocrinology 83: 783-790.

Kvols LK (1986) Metastatic carcinoid tumours and the carcinoid syndrome. American Journal of Medicine 81: 49-55.

Kvols LK, Moertel CG, O'Connell MJ et al (1986) Treatment of the malignant carcinoid syndrome. Evaluation of a long-acting somatostatin analogue. New England Journal of Medicine 315: 663-666.

Kvols LK, Buck M, Moertel CG et al (1987) Treatment of metastatic islet cell carcinoma with a somatostatin analogue (SMS 201-995). Annals of Internal Medicine 107: 162-168.

Lamberts SWJ (1988) The role of somatostatin in the regulation of anterior pituitary hormone secretion and the use of its analogs in the treatment of human pituitary tumors. Endocrine Reviews 9: 417-436.

Lamberts SWJ, Oosterom, R, Neufeld M \& del Pozo E (1985a) The somatostatin analog SMS 201-995 induces long-acting inhibition of growth hormone secretion without rebound hypersecretion in acromegalic patients. The Journal of Clinical Endocrinology and Metabolism 60: 1161-1165.

Lamberts SWJ, Uitterlinden P, Verschoor L, van Dongen KJ \& del Pozo E (1985b) Long-term treatment of acromegaly with the somatostatin analogue SMS 201-995. New England Journal of Medicine 313: 1576-1580.

Lamberts SWJ, Reubi J-C, Uitterlinden P et al (1986a) Studies on the mechanism of action of the inhibitory effect of the somatostatin analog SMS 201-995 on the growth of the PRL/ACTH pituitary tumor 7315a. Endocrinology 118: 2188-2194.

Lamberts SWJ, Zweens M, Klijn JGM et al (1986b) The sensitivity of growth hormone and prolactin secretion for the somatostatin analogue SMS 201-995 in patients with prolactinomas and acromegaly. Clinical Endocrinology 25: 201-212.

Lamberts SWJ, Zweens M, Verschoor L \& del Pozo E (1986c) A comparison among the growth hormone-lowering effects in acromegaly of the somatostatin analog SMS 201-995, bromocriptine, and the combination of both drugs. The Journal of Clinical Endocrinology and Metabolism 63: 16-19.

Lamberts SWJ, Koper JW \& Reubi J-C (1987a) Potential role of somatostatin analogues in the treatment of cancer. European Journal of Clinical Investigation 17: 281-287. 
Lamberts SWJ, Uitterlinden P \& del Pozo E (1987b) Sandostatin (SMS 201-995) induces a continuous further decline in circulating growth hormone and somatomedin-C during therapy of acromegalic patients for over two years. The Journal of Clinical Endocrinology and Metabolism 65: 703-710.

Lamberts SWJ, Verleun T, Zuiderwijk JM \& Oosterom R (1987c) The effect of the somatostatin analog SMS 201-995 on normal growth hormone secretion in the rat. A comparison with the effect of bromocriptine on normal prolactin secretion. Acta Endocrinologica 115: 196-202.

Lamberts SWJ, Pieters GFFM, Metselaar HJ et al (1988a) Development of resistance to a long-acting somatostatin analogue during treatment of two patients with metastatic endocrine pancreatic tumours. Acta Endocrinologica 119: 561-566.

Lamberts SWJ, Tilanus HW, Klooswijk AIJ et al (1988b) Successful treatment with SMS 201-995 of Cushing's syndrome caused by ectopic adrenocorticotropin secretion from a metastatic gastrin-secreting pancreatic islet cell carcinoma. The Journal of Clinical Endocrinology and Metabolism 67: 1080-1083.

Lamberts SWJ, Uitterlinden P, Schuijff PC \& Klijn JGM (1988c) Therapy of acromegaly with Sandostatin: the predictive value of an acute test, the value of serum somatomedin-C measurements in dose adjustment and the definition of a biochemical 'cure'. Clinical Endocrinology 29: 411-420.

Lamberts SWJ, Uitterlinden P \& Klijn JGM (1989a) The effect of the long-acting somatostatin analog SMS 201-995 on ACTH secretion in Nelson's syndrome and Cushing's disease. Acta Endocrinologica 120: 760-766.

Lamberts SWJ, Zuyderwijk J, den Holder F, van Koetsveld P \& Hofland L (1989b) Studies on the conditions determining the inhibitory effect of somatostatin on adrenocorticotropin, prolactin and thyrotropin release by cultured rat pituitary cells. Neuroendocrinology 50: 44-50.

Lamers CBHW, Lind T, Moberg S, Jansen JBMJ \& Olbe I (1984) Omeprazole in ZollingerEllison syndrome: effects of a single dose and of long-term treatment in patients resistant to histamine $\mathrm{H}_{2}$-receptor antagonist. New England Journal of Medicine 310: 758-761.

Liebow C, Hierowski M \& Sapin K (1986) Hormonal control of pancreatic cancer growth. Pancreas 1: 44-48.

Mascardo RN \& Sherline P (1982) Somatostatin inhibits rapid centrosomal separation and cell proliferation induced by epidermal growth factor. Endocrinology 111: 1394-1396.

Maton PM, Camilleri M, Griffin G et al (1983) Role of hepatic artery embolisation in the carcinoid syndrome. British Medical Journal 287: 932-935.

Maton PM, O'Dorisio TM, Howe BA et al (1985) Effect of a long-acting somatostatin analogue (SMS 201-995) in patients with pancreatic cholera. New England Journal of Medicine 312: $17-21$.

Moertel CG, Hanley JA \& Johnson LA (1980) Streptozocin alone compared with streptozocin plus fluorouracil in the treatment of advanced islet-cell carcinoma. New England Journal of Medicine 303: 1189-1194.

O'Dorisio TM (1986) Neuroendocrine disorders of the gastroenteropancreatic system. Clinical applications of the somatostatin analogue SMS 201-995. American Journal of Medicine 81 (6B): 1-101.

Oppizzi G, Petroncini MM \& Dallabonzana D (1986) Relationship between somatomedin-C and growth hormone levels in acromegaly: basal and dynamic evaluation. The Journal of Clinical Endocrinology and Metabolism 63: 1348-1353.

Palmer Smith J \& Solomon TE (1988) Effects of gastrin, proglumide, and somatostatin on growth of human colon cancer. Gastroenterology 95: 1541-1548.

Papotti M, Maci L, Bussolati G \& Reubi J-C (1989) Correlative study on neuro-endocrine differentiation and presence of somatostatin receptors in breast carcinomas. International Journal of Cancer 43: 365-370.

Pearse AGE, Polak JM \& Heath CM (1974) Polypeptide hormone production by 'carcinoid' apudomas and their relevant cytochemistry. Virchows Archives (Cell Pathology) 16: 95-109.

Plewe C, Beyer J, Krause U, Neufeld M \& del Pozo E (1984) Long-acting and selective suppression of growth hormone secretion by somatostatin analogue SMS 201-995 in acromegaly. Lancet ii: 782-784.

del Pozo E, Neufeld M \& Schlutter K (1986) Endocrine profile of a long-acting somatostatin 
derivative SMS 201-995. Study in normal volunteers following subcutaneous administration. Acta Endocrinologica 111: 433-439.

de Quijada MG, Redding TW, Coy DH, Torres-Alleman I \& Schally AV (1983) Inhibition of growth of a prolactin-secreting pituitary tumor in rats by analogs of luteinizing hormonereleasing hormone and somatostatin. Proceedings of the National Academy of Sciences USA 80: $3485-3488$.

Redding TW \& Schally AV (1983) Inhibition of growth of the transplantable rat chondrosarcoma by analogs of hypothalamic hormones. Proceedings of the National Academy of Sciences USA 80: 1078-1082.

Redding TW \& Schally AV (1984) Inhibition of growth of pancreatic carcinomas in animals models by analogs of hypothalamic hormones. Proceedings of the National Academy of Sciences USA 81: 248-252.

Reichlin S (1983a) Somatostatin (part 1). New England Journal of Medicine 309: 1495-1501.

Reichlin S (1983b) Somatostatin (part 2). New England Journal of Medicine 309: 1556-1563.

Reubi J-C (1985) A somatostatin analogue inhibits chondrosarcoma and insulinoma tumour growth. Acta Endocrinologica 109: 108-114.

Reubi J-C \& Landolt AM (1984) High density of somatostatin receptors in pituitary tumours from acromegalic patients. The Journal of Clinical Endocrinology and Metabolism 59: $1148-1153$.

Reubi J-C \& Landolt AM (1989) The growth hormone responses to octreotide in acromegaly correlate with adenoma somatostatin receptor status. The Journal of Clinical Endocrinology and Metabolism 68: 844-850.

Reubi J-C \& Maurer R (1985) Autoradiographic mapping of somatostatin receptors in the rat central nervous system and pituitary. Neuroscience 15: 1183-1193.

Reubi J-C, Cortes R, Maurer R, Probst A \& Palacios JM (1986a) Distribution of somatostatin receptors in the human brain: an autoradiographic study. Neuroscience 18: 329-346.

Reubi J-C, Maurer R, Klijn JGM et al (1986b) High incidence of somatostatin receptors in human meningiomas: biochemical characterization. The Journal of Clinical Endocrinology and Metabolism 63: 433-438.

Reubi J-C, Maurer R \& Lamberts SWJ (1986c) Somatostatin binding sites in human leptomeninx. Neuroscience Letters 70: 183-186.

Reubi J-C, Hacki WH \& Lamberts SWJ (1987a) Hormone-producing gastrointestinal tumors contain a high density of somatostatin receptors. The Journal of Clinical Endocrinology and Metabolism 65: 1127-1134.

Reubi J-C, Heitz PU \& Landolt AM (1987b) Visualization of somatostatin receptors and correlation with immunoreactive growth hormone and prolactin in human pituitary adenomas: evidence for different tumor subclasses. The Journal of Clinical Endocrinology and Metabolism 65: 65-73.

Reubi J-C, Lang W, Maurer R, Koper WJ \& Lamberts SWJ (1987c) Distribution and biochemical characterization of somatostatin receptors in tumors of the human central nervous system. Cancer Research 47: 5758-5764.

Reubi J-C, Maurer R, von Werder K et al (1987d) Somatostatin receptors in human endocrine tumors. Cancer Research 47: 551-558.

Reubi J-C, Horisberger U, Essed CE et al (1988) Absence of somatostatin receptors in human exocrine pancreatic adenocarcinomas. Gastroenterology 95: 760-763.

Reubi J-C, Horisberger U, Lang W et al (1989) Coincidence of EGF receptors and somatostatin receptors in meningiomas but inverse, differentiation-dependent relationship in glial tumors. American Journal of Pathology 134: 337-344.

Ruszniewski P, Girard F, Benamouzig R, Mignon M \& Bonfils S (1988) Long acting somatostatin treatment of paraneoplastic Cushing's syndrome in a case of Zollinger-Ellison syndrome. Gut 29: 838-842.

Scambia G, Panici PB, Baiocchi G et al (1988) Antiproliferative effects of somatostatin and the somatostatin analog SMS 201-995 on three human breast cancer cell lines. Journal of Cancer Research Clinical Oncology 114: 306-308.

Schally AV (1988) Oncological applications of somatostatin analogues. Cancer Research 48: $6977-6985$.

Setyono-Han B, Henkelman MS, Foekens JA \& Klijn JGM (1987) Direct inhibitory effects of somatostatin (analogues) on the growth of human breast cancer cells. Cancer Research 47: $1566-1570$. 
Siegel RA, Tolcsvai L \& Rudin M (1988) Partial inhibition of the growth of transplanted Dunning rat prostate tumors with the long-acting somatostatin analogue Sandostatin (SMS 201-995). Cancer Research 48: 4651-4655.

Stefanini P, Carboni M, Patrassi N \& Basoli A (1974) Beta-islet tumors of the pancreas: results of a study on 1067 cases. Surgery 75: 597-609.

Taylor JE, Bogden AE, Moreau J-P \& Coy DH (1988a) In vitro and in vivo inhibition of human small cell lung carcinoma (NCI-H69) growth by a somatostatin analogue. Biochemical and Biophysical Research Communications 153: 81-86.

Taylor JE, Coy DH \& Moreau JP (1988b) High affinity binding of [ $\left.{ }^{125}\right]-$ Tyr $^{11}$ ]Somatostatin-14 to human small cell lung carcinoma (NCI-H69). Life Science 43: 421-427.

Upp JR, Olsen D, Graeme BS et al (1988) Inhibition of growth of two human pancreatic adenocarcinomas in vivo by somatostatin analog SMS 201-995. The American Journal of Surgery 155: 29-35.

Vale W, Rivier J, Ling N \& Brown M (1978) Somatostatin analogs. Metabolism 27 (supplement): 1391-1401.

Viguerie N, Estire JP, Susini C et al (1987) Postreceptor effects mediated by somatostatin. Biochemical and Biophysical Research Communications 147: 942-948.

Vinik AI, Tsai ST, Moattari AR et al (1986) Somatostatin analogue (SMS 201-995) in the management of gastroenteropancreatic tumors and diarrhea syndrome. American Journal of Medicine 81 (6B): 23-41.

Williams G, Burrin JM, Ball JA, Joplin GF \& Bloom SR (1986) Effective and lasting growthhormone suppression in active acromegaly with oral administration of somatostatin analogue SMS 201-995. Lancet ii: 774-777.

Williams G, Anderson JV, Williams SJ \& Bloom SR (1987) Clinical evaluation of SMS 201-995: long-term treatment in gut neuroendocrine tumours, efficacy of oral administration, and possible use in non-tumoural inappropriate TSH hypersecretion. Acta Endocrinologica 286(supplement): 26-36.

Woltering EA, Mozell EJ, O'Dorisio TM, Fletcher WS \& Howe B (1988) Suppression of primary and secondary peptides with somatostatin analog in the therapy of functional endocrine tumors. Surgery, Gynecology \& Obstetrics 167: 453-462.

Wood SM, Kraenzlin ME, Adrian TE \& Bloom SR (1985) Treatment of patients with pancreatic endocrine tumours using a new long-acting somatostatin analogue SMS 201995: symptomatic and peptide responses. Gut 26: 438-444.

Wynick D, Williams SJ \& Bloom SR (1988) Symptomatic secondary hormone syndromes in patients with established malignant pancreatic endocrine tumors. New England Journal of Medicine 319: 605-607. 